\title{
CORRESPONDENCE
}

\author{
Visual hallucinations in children \\ receiving decongestants \\ J Bain, FRCGP; P C Drennan, MB; M G \\ Miller, MRCP. . . . . . . . . . . . . 1688 \\ Myocardial depression in streptococcal \\ cellulitis \\ Penelope J Redding, LRCP, and others. . . 1688 \\ Wilson's disease \\ J M Walshe, FRCP; G Robbins, MRCP, \\ and R P Britt, FRCPATH . . . . . . . . . . . 1689 \\ Medical education \\ Trisha Greenhalgh, MB; S L Barley, \\ MRCGP; Nicholas Gold, MB... . . . . . . . 1689 \\ Neuroleptic malignant syndrome \\ K Reddi, MRCPSYCH ; R Grant, MB . . . . . . 1690 \\ Psychiatry and violent offenders \\ M P I Weller, MRCPSYCH. . . . . . . . . . . 1690 \\ The Wormwood Scrubs Annexe \\ C R Clark, PHD, and Judith F E David, \\ MRCPSYCH .................... 1691
}

General practitioner hospitals: coming or going?

$\mathrm{R}$ Hall, $M B$, and others; W A Shearman

LRCP . . . . . . . . . . . . . . . . . . . . . . . 1691

Planned and unplanned deliveries at

home

Marjorie Tew, MA................ 1691

Immunisation, rehydration, and

transfusion

J A F Napier, MRCPATH. . . . . . . . . . 1692

Late mortality after vagotomy and drainage for duodenal ulcer

N J Bundred, MB, and others. . . . . . . . 1692

Treatment of myopia

T S-B Kelly, FRCS. .

Negative selection of patients for

dialysis and transplantation in the

United Kingdom

V Parsons, DM, and others.

\section{Overseas doctors}

S Roy-Chowdhury............... 1693

Points Standardisation of oral anticoagulant

treatment (L Poller; $N$ N Sen); Heroin addiction (Ann Dally; F A Whitlock) .... 1693

Patient information booklets (P J M Sloan); Major disaster planning (I M R Lowdon);

Poor management of unconscious rugby player watched by millions (J Adno); Salicylate intoxication in the elderly due to benorylate (J S McCracken); When the bowels turn to water (E W van Heyningen); Loss of vision (D McLeod); Medicine in the workplace (A Semmence and Dorothy Radwanski); Making an appointment system work (M J White); Kielland's forceps delivery (Conor Carr); Alcohol withdrawal and epilepsy (Margaret Patterson); Death certification in general practice (C B Freer); Learning to live with cash limits (D P Murray). . . . . . . . . . . . 1694

\begin{abstract}
We may shorten letters to the editor unless the authors specifically state that we may not. This is so that we can offer our readers as wide a selection of letters as possible. We receive so many letters each week that we have to omit some of them. Letters must be typed with double spacing between lines and must be signed personally by all their authors, who should include their degrees. Letters critical of a paper may be sent to the authors of the paper so that their reply may appear in the same issue.

Correspondents should present their references in the Vancouver style (see examples in these columns). In particular, the names and initials of all authors must be given unless there are more than six, when only the first three should be given, followed by et al; and the first and last page numbers of articles and chapters should be included.
\end{abstract}

\section{Visual hallucinations in children receiving decongestants}

SIR,-Dr R J Sankey and others' report (5 May, p 1369) about visual hallucinations in children receiving a combination of pseudoephedrine and triprolidine (Actifed) reminds us that the time honoured cough bottle is not without side effects. In a trial of pseudoephedrine, triprolidine, and placebo in the treatment of respiratory symptoms associated with otitis media $6 \%$ of the children had to be withdrawn because of side effects including irritability, dizziness, general malaise, and nightmares. ${ }^{1}$ Decongestant antihistamine mixtures are second only to antibiotics in prescriptions issued to children. They are often given for their presumed sedative effects, but there is no evidence that they are more effective than placebo in treating sleep disturbances in children with respiratory symptoms. ${ }^{1}$

Studying the efficacy of a decongestant antihistamine combination in the treatment of secretory otitis media Cantekin and others found that $24^{\circ}$ of children on the active drug had more side effects including irritability compared with $9 \%$ of those on placebo. ${ }^{2}$ More serious reactions may be rare, although dystonic reactions in a child taking Dimotapp Elixir (brompheniramine, phenylephrine, and phenylpropanolamine) have been reported. ${ }^{3}$ Although visual hallucinations and dystonic reactions may be rare side effects of decongestant antihistamine mixtures the widespread prescribing of these drugs has to be more seriously questioned.

J BAIN

Primary Medical Care,

Faculty of Medicine,

niversity of Southampton
Bain DJG. Can the clinical course of acute otitis media be modified by systemic decongestant or antihistamine treatment ? Br Med f 1983;287:654-6. Cantekin EI, Mandell EM, Bluestone CD, et al. Lack of efficacy of a decongestant-antihistamine children. N Engl F Med 1983:308:297-301.

Lewith GT, Davidson F Dystonic reactions to Dimotapp Elixir. $7 R$ Coll Gen Pract 1981;31:241.

SIR,-Some weeks ago I gave our $2 \frac{1}{2}$ year old son $5 \mathrm{ml}$ of Actifed (triprolidine and pseudoephedrine) before bed because of an irritating cough and runny nose. About 2 am he awoke crying saying that there were ants crawling in his bed. When I went into his bedroom he was sitting up, with a very flushed face, pointing out areas on his bed and the walls where he thought ants and spiders were crawling. I assumed this to be associated with pyrexia.

The next night, although his catarrhal symptoms were the same, he did not receive Actifed because it was forgotten. There was no early morning waking, but the following night when another $5 \mathrm{ml}$ dose was given the hallucinatory period was repeated.

$\mathrm{He}$ has had Actifed before but probably not for some nine months, and on reflection it was common for him to wake at around 2 am and appear to be agitated but settle with a glass of water. At that age his language was not good, and it is possible that he was having hallucinations but unable to tell us.

Weybridge Health Centre,

Weybridge,

Surrey KT13 8DU

SIR,-My wife asked me if I had heard of Actifed (triprolidine and pseudoephedrine)

\section{P C DRENNAN}

causing odd behaviour in children on the same day that I read the article by Dr R J Sankey and others (5 May, p 1369). I would like to report two further cases and a possible third.

One 4 year old girl and one 5 year old girl (from different families) were prescribed Actifed syrup $5 \mathrm{ml}$ and penicillin $125 \mathrm{mg}$ four times daily to treat persistent colds associated with serous otitis media. Both girls had unusual night terrors during which they did not respond to their parents. The 5 year old complained of a rabbit staring at her at the end of her bed, and a few nights later she complained of yellow insects biting holes in her. Both girls were unusually aggressive during the day.

The mother of a five year old boy said that her son also developed night terrors while taking Actifed syrup which ended when she stopped the medicine.

None of the parents reported the symptoms to the prescribing doctor, as they thought it would be attributed to the illness or shrugged off. It is likely these symptoms are underreported, and efforts should be made to inquire about them more often in children prescribed this group of drugs.

M G MILLER

St James's University Hospital,

\section{Myocardial depression in streptococcal cellulitis}

SIR,-Following Dr J D Edwards's and Dr P M Schofield's paper (17 March, p 816) we report a similar case.

A 27 year old woman became unwell 48 hours 
after an uneventful lower segment caesarean section. She had a tachycardia, an inflamed wound, and some vulval swelling. Blood was taken for culture and intravenous cephaloridine and metronidazole were started. She deteriorated rapidly and became pale and cyanosed with an unrecordable blood pressure. Her abdomen was distended and there were no bowel sounds. She was resuscitated with intravenous fluids, oxygen, and hydrocortisone (100 mg), and transferred to the Western Infirmary, Glasgow.

On arrival her wound was tender, dusky, and warm, with blistering of the skin. She again became shocked with a blood pressure of $90 / 60 \mathrm{~mm} \mathrm{Hg}$, intensive vasoconstriction, and oliguria. Her core temperature was $39.5^{\circ} \mathrm{C}$. The cephaloridine was stopped, and cefotaxime and benzylpenicillin added to the metronidazole. At subsequent laparotomy the internal organs were found to be intact and no intra-abdominal collections identified. A total of 3.51 of fluid was given together with further hydrocortisone $(100 \mathrm{mg})$. In the intensive therapy unit she was given a further 31 of fluid and over the next eight hours she regained normal haemodynamic values.

Pus collected from the wound at laparotomy contained numerous polymorphs and chaining Gram positive cocci. Intravenous benzylpenicillin (2 MU four hourly) was continued. Subsequently a Streptococcus pyogenes ( $\beta$ haemolytic Lancefield group A) was isolated. She was extubated and haemodynamically stable within 24 hours but remained pyrexial with cellulitis around her wound. Within 48 hours this covered her lower abdomen and extended down her left thigh. The benzylpenicillin was increased to $4 \mathrm{MU}$ four hourly. Over the next six days her temperature returned to normal, and the cellulitis resolved. An area of necrosis below the wound subsequently required grafting.

This case shows the severity of the haemodynamic disturbance associated with Str pyogenes. Appreciation of this act should lead to immediate and aggressive resuscitation with fluids, oxygen, and benzylpenicillin. Myocardial depression is not specific to streptococcal infection and may be observed in many patients in whom shock is severe and prolonged. ${ }^{1}$

Penelope J Redding THERESA MCGOVERN I MCA LEDINGHAM

\section{Western Infirmary,}

' Ledingham I McA. Heart failure in experimental
refractory shock. Intensive Care Med 1976;2:111-7.

\section{Wilson's disease}

SIR,-Dr David Parkes suggests that there may be between 250 and 1500 cases of Wilson's disease in Britain and that 1000 of these cases may be unrecognised (21 April, p 1180). In their recent monograph on the disease Dr I $H$ Scheinberg and $\mathrm{Dr} I$ Sternlieb ${ }^{1}$ summarised evidence for the prevalence of the disease and hence the gene frequency in populations where cosanguinity has not biased the results. ${ }^{1}$ With increasing awareness of the disease and its pleomorphic manifestations together with increasingly sophisticated diagnostic techniques the rate of accurate diagnosis has increased.

In 1953 Bearn calculated an incidence of one in

Age distribution of cases of Wilson's disease in East Anglia

\begin{tabular}{lrrrrrr}
\hline Age & \multicolumn{1}{c}{$0-4$} & \multicolumn{1}{c}{$5-15$} & $16-24$ & \multicolumn{1}{c}{$25-34$} & \multicolumn{1}{c}{$35-44$} & Total \\
\hline Population & 207584 & 557084 & 441672 & 492206 & 421743 & 3376981 \\
No of patients (age in 1981) & 0 & 1 & 9 & 13 & 1 & 24 \\
No of patients (age at onset) & 0 & 10 & 10 & 4 & 0 & 24
\end{tabular}
suggested some scepticism of the figures. Cambridge drains most of the population-apart from where Essex verges on London.

The area considered is greater than the administrative East Anglian region of Cambridgeshire, Norfolk, and Suffolk. The population under consideration was in the 1981 census 3376981 and has probably not varied much subsequently. Twenty four patients are known, and the diagnosis has been confirmed in all cases. I have broken down the patients into the cohorts used in the 1981 census figures, which is necessary as the disease does not present in the youngest age group and could not be expected in the older age groups (table). Patients over 45 would probably have been missed because of diagnostic shortcomings.

Taking the peak incidence for presentation as the two cohorts $5-15$ and $16-24$ we find 20 patients in a population of 998720 , and there were 23 patients in the age groups 16-24 and 25-34 among 933878 people. Both these sets of figures are not so far from the 29 in a million of the East Germany survey. ${ }^{4}$ Some patients may have died or may still remain undiagnosed, while some will have been referred elsewhere. Thus the figures are an underestimate. No consanguinity was recorded to bias the figures.

If the incidence of Wilson's disease for East Anglia is translated to the whole country there must indeed be more than 1000 patients, most of whom presumably remain undiagnosed. It would be interesting to know how many could be brought to light by a detailed survey in paediatric, neurological, and gastroenterological clinics among patients aged 5 to 25 years. In addition a search of psychiatric clinics for a slightly older age group might produce a few additional cases.

Department of Medicine,

University of Cambridge Clinical School,

Cambridge CB2 2QQ

${ }^{1}$ Scheinberg IH, Sternlieb I. Wilson's disease: majo 1984.

${ }^{2}$ Bearn AG. A genetical analysis of thirty families with Wilson's disease (hepatolenticular degeneration). Ann Hum Genet 1960;24:33-43.

Sternlieb I, Scheinberg IH. The prevention of Wilson's disease in asymptomatic patients. $N$ Engl Med 1968;278:352-9.

${ }^{4}$ Bachmann H, Lossner J, Gruss B, Ruchholtz U. Die epidemiologie der Wilsonschen Erkrankung in de DDR und die derzeitige Problematik einer populationgenetischen Bearbeitung.
Med Psychol 1979;31:393-400.

${ }^{5}$ Walshe JM. Hudson Memorial Lecture: Wilson's disease: genetics and biochemistry-their relevance to therapy. $\mathcal{F}$ Inher Metab Dis $1983 ; 6: 51-8$.

SIR,-Dr D Parkes emphasised the importance of diagnosing Wilson's disease in view of the a million with a gene frequency of one in 500 of the population. ${ }^{2}$ By 1968 the estimate had risen to one in 200000 with a carrier rate of one in $224 .^{3}$ By 1979 the figure had reached 30 in a million with a gene frequency of $0.53 \%, 4$ which led me to comment that if this figure were to be transposed to this country "there may be as many as 1600 cases of Wilson's disease in Britain. As the majority of these are probably not correctly diagnosed they will therefore die of their disease; this suggests that our diagnostic failures amount to something approaching a minor medical disaster." 5 This statement

East Anglia, however, may well be ideal for estimating the incidence of the disease in Britain. We can count accurately diagnosed cases and need not rely on statistics gathered from several centres or from death certificates. The population is stable and largely rural, and the university hospital at problems in internalmedicine. Philadelphia: Saunders,

reatly improved prognosis with correct treatment (21 April, p 1180). We draw attention to a mode of presentation he did not discuss.

A previously well 14 year old Indian girl with no relevant family history presented with severe acute haemolysis (haemoglobin concentration $6.39 \mathrm{~g} / \mathrm{dl}$, reticulocytes $14 \%$ ). Examination showed severe jaundice but no stigmata of chronic liver disease. There was no neuropsychiatric disturbance. A peripheral blood film showed basophilic stippling, anisocytosis, and occasional erythroblasts. Bilirubin concentration was $40 \mu \mathrm{mol} / 1(2.3 \mathrm{mg} / 100 \mathrm{ml})$ (normal $<15 \mu \mathrm{mol} / 1(0.9 \mathrm{mg} / 100 \mathrm{ml})$ ), alanine transaminase concentration was $124 \mathrm{IU} / 1$ (normal 2-20 IU /1), and serum albumin concentration was $25 \mathrm{~g} / 1$ (normal 37-53 g/1). Drug induced haemolysis, viral infection, malaria, autoimmune disease, and red cell enzymopathy were excluded. Wilson's disease was diagnosed by finding bilateral Kayser-Fleischer rings and urinary copper excretion of $5 \cdot 1$ and $28 \cdot 3 \mu \mathrm{mol} / 24$ hours $(0.3$ and $1.7 \mathrm{mg} / 24$ hours) (normal $<1 \mu \mathrm{mol}$ $0.06 \mathrm{mg} / 24$ hours). Serum copper and caeruloplasmin concentrations were unexpectedly normal. This was ascribed to increased release during hepatic necrosis. One further haemolytic crisis has occurred. Two asymptomatic siblings were shown to have Wilson's disease.

Acute recurrent haemolysis is a recognised feature of Wilson's disease but an uncommon mode of presentation. ${ }^{1}$ It may be due to the toxic oxidant effect of the massive release of copper from the liver. ${ }^{2}$ Wilson's disease should be considered in patients presenting with acute haemolysis, particularly if liver dysfunction is present.

G RoBBINS

R P BRITT

Hillingdon Hospital,

Uxbridge,
Middlesex UB8 3NN ' McIntyre N, Clink HM, Levi AJ, Cummings JN, S Engl f Med 1967;276:439-44.

2 Deiss A, Lee RR, Cartwright GE. Hemolytic anemia in Wilson's disease. Ann Intern Med 1970;73: 413-8.

\section{Medical education}

SIR,-It is true that undergraduate medical training instructs rather than educates and both creates and rewards tunnel vision. It is probably true that new medical graduates are less equipped than ever before to deal with the problems in acute medicine. I doubt, however, that Dr J Horder and others' proposal for yet another period of structured professional training with formal assessment is the solution (19 May, $p$ 1507).

My preregistration year is almost over. Most of the problems which confuse and haunt me could never be expressed in any textbook. I have mended oscilloscopes, advised male homosexuals on their technique, hitch hiked back from peripheral clinics when strikes affected transport, rummaged through patients' lockers in search of alcohol, and defended myself against physical and phychological assault. The skills which I am coming to acquire are so intangible that they disappear when I try to define them. The best and probably the only way to gain confidence and skill is to be thrown in at the deep end. One can no longer, however, simply "go and look it up" after the event. Today's medical problems demand a delicate blend of intellectual, emotional, technical, and interpersonal skills. Dr Horder and others have recognised this, but I find their proposed solution inappropriate.

From the shop floor, I see two obstacles to 